\title{
The decline of combustibility of heat-insulating composite plates from plant wastes
}

\author{
Alexandr Ibragimov ${ }^{1}$, Andrey Titunin ${ }^{2}$, Tatiana Vachnina $^{2}$, Irina Susoeva ${ }^{*}, 2$ \\ ${ }^{1}$ Moscow State University of Civil Engineering, Yaroslavskoe shosse, 26, Moscow, 129337, Russia \\ ${ }^{2}$ Kostroma State University, 17, Dzerzhinsky, Kostroma 156005, Russia
}

\begin{abstract}
The structure and factors of the process of production of heatinsulating composite plate materials from the waste of spinning of plant fibers are being developed. A disadvantage of the cellulose-containing filler composites is their increased flammability. The stages of thermal destruction of cellulose are considered. To determine the characteristics of the material that affect their fire hazard properties, the differential scanning calorimetry method was used. The paper substantiates the use of the method of introduction of fire retardant at the stage of formation the structure of composite. To reduce the flammability of composite materials from plant raw materials, it was suggested to use ammonium fluoride. The results of the determination of the degree of damage by mass in the case of burning in a "ceramic combustion chamber" of samples of a composite material with filler from irrecoverable waste produced by cotton and linen fibers are obtained. It has been established that the use of ammonium fluoride for the manufacture of heat-insulating composite plate materials from the irrecoverable waste produced by cotton and linen fibers makes it possible to obtain material with a degree of damage by mass of not more than $22 \%$. Key words: cotton, flax, spinning waste, cellulose, thermal destruction, differential scanning calorimetry, composite materials, loss of mass in combustion, ammonium fluoride.
\end{abstract}

\section{Introduction}

The use of plant wastes for the manufacture of heat-insulating board materials is relevant both from the point of view of resource-saving and within the framework of improving the ecological safety of the production of heat-insulating materials. The use of plant waste produced by local industry for the production of building materials allows us to solve a whole range of tasks: diversification of raw materials for the manufacture of thermal insulation materials, involvement in the production of plant materials of the category of irrecoverable waste, reducing the pressure of waste on the biosphere.

The plant materials traditionally used in construction are primarily wood, as well as the waste of its processing $[1,2]$. Annual wastes are less commonly used in the production of construction materials, although this type of plant material is characterized by availability, reproducibility, environmental friendliness and a number of valuable technical qualities.

*Corresponding author: i.susoeva@yandex.ru 
Secondary waste spinning industries, along with such plant materials as fire, straw, can be used for the manufacture of heat-insulating building board materials [3-5]. In the study, the structure and factors of the production process of heat-insulating composite plates materials from irrecoverable waste of flax and cotton spinning [6].

The main disadvantage of plant materials is their flammability, the ability to spread the flame with the release of a large amount of heat and toxic gaseous combustion products. This increases the risk of a fire hazard situation. In the development of composite thermal insulation materials based on plant raw materials, research in the field of reducing the combustibility of these materials is of particular relevance [7-11].

The main fuel component of the waste is cellulose - an organic polymer of biological origin with the general formula $\left(\mathrm{C}_{6} \mathrm{H}_{10} \mathrm{O}_{5}\right) \mathrm{n}$, the cellulose macromolecule is constructed of glucopyranose units. Combustion of cellulose-containing materials is a chemical oxidationreduction process, accompanied by the release of heat and a number of products of reactions taking place during this process. Under the influence of high temperatures, the destruction of cellulose passes through a series of successive stages. At temperatures of $200 \ldots 230^{\circ} \mathrm{C}$, the amorphous part mainly destroys, and the crystalline part is retained. At the same time, the degree of polymerization decreases quite rapidly. The cleavage of chains by glycosidic bonds is accompanied by dehydration and oxidation reactions. With a further increase in temperature to $270 \ldots 280{ }^{\circ} \mathrm{C}$ and higher, the crystalline part begins to degrade, with the formation of levoglucosan as the main product of degradation. At a temperature of about $340{ }^{\circ} \mathrm{C}$, complete amorphization occurs with a weight loss of up to $60 \%$. Then the transition of the amorphized structure of cellulose into carbonized begins, the coal structure is formed.

To prevent the spread of fire in buildings and structures with heat-insulating cellulosecontaining materials, it is necessary to use fire-retardant measures, the most common of which is the use of flame retardants, which differ in the way they are used and in the fire protection mechanism. For such cellulose-containing materials as wood, the methods of surface and deep impregnation with flame retardants, as well as the application of fireproof paint coatings (intumescent) type. Constructive fire protection (coatings, heat-reflecting coatings) is technologically most feasible, but the middle layer of the material remains unprotected, and when the integrity of the coating is violated, the fire resistance is sharply reduced.

For composite plate materials from discrete cellulose-containing particles, the introduction of flame retardants into the composition at the stage of structure formation of the material is a more effective method of protection.

The most common flame retardants are inorganic compounds (such as aluminum hydroxide, magnesium hydroxide), halogen-containing and phosphorus-containing compounds. The group of hydroxides of metals and other inorganic flame retardants accounts for approximately $50 \%$ of the total world production of flame retardants [12], intumescent [13-16]. Organophosphate flame retardants, mostly ether derivatives, account for approximately $20 \%$ of the total world production [17], nitrogen [18].

Halogen-containing (chlorine and bromine) flame retardants represent a significant part of all flame retardants, they are one of the most popular types of flame retardants $[19,20]$. In general, a group of halogen-containing flame retardants accounts for about $25 \%$ of the world production of flame retardants. These fire retardants are characterized by low cost and efficiency [21-25]. Halogen-containing flame retardants act mainly through chemical interference in processes that occur through the radical chain mechanism in the gas phase during combustion, preventing the combustion process at various stages of the process (heating, decomposition, ignition) [26, 27]. 


\section{Methods}

Different types of plant materials have differences in the index of thermal resistance, therefore, an experimental study of fire-hazardous properties applied to a concrete plant filler of composite heat-insulating materials - irrecoverable waste of spinning of flax and cotton.The loss of mass and the rate of mass loss during thermal exposure are the most important characteristics of the combustibility of materials [28], the ability to evaluate these and other indicators gives a thermal analysis of the material [29, 30].

In this paper, the method of differential scanning calorimetry (DSC) was used to determine the material characteristics that affect their fire-dangerous properties. DSC is a modern version of thermal analysis, the method is widely used [31, 32]. In the DSC method, the heat is determined through the heat flux, measured by the temperature difference at two points of the measuring system at one time. The thermographic curves were taken at the synchronous thermal analysis unit NETZSCH STA 449 F3 Jupiter, combined with the FT-IR attachment. The thermal analysis was carried out in the range $20 \ldots 600{ }^{\circ} \mathrm{C}$ at a heating rate of $10^{\circ} \mathrm{C} / \mathrm{min}$, the mass of the test samples was $1 . .5 \mathrm{mg}$.

In the study, composite heat-insulating plates were manufactured from the irrecoverable waste products of flax and cotton fibers based on phenol- and urea-formaldehyde resins using the technology of wood-fiber slabs for wet production. As a retarder burning plates from the waste spinning of plant fibers used ammonium fluoride. The mass fraction of the flame retardant ranged from 10 to $30 \%$.

The flammability parameters were determined in accordance with the requirements of the Russian Standard 30244-94 "Building Materials. Test methods for flammability "ceramic combustion chamber" in accordance with Russian Standard 53292-2009.

\section{Results and Discussion}

Thermal analysis results - curves of thermogravimetry (TG) and differential scanning calorimetry (DSC) for cotton fiber spinning waste are shown in Fig. 1, for flax fiber waste in Fig. 2.

In the interval $50 \ldots 218.5^{\circ} \mathrm{C}$ (the TG curve of cotton waste), $50 \ldots 284.7^{\circ} \mathrm{C}$ (the TG curve of flax waste), sorption moisture is removed, the mass loss of the material is $10 \%$. In addition to the removal of sorption moisture and the thermal destruction of hemicelluloses, weight loss is affected by the processes of destruction of the amorphous part of cellulose starting in the interval $200 \ldots 230{ }^{\circ} \mathrm{C}$. With dehydration, the cleavage of cellulose chains along glycosidic bonds and the partial decomposition of glucopyranose links occur.

Exothermic peaks - for cotton waste at a temperature of $316.98^{\circ} \mathrm{C}, 370.25{ }^{\circ} \mathrm{C}$ for flax wastes characterize the specific heat of the thermolysis process $(1221 \mathrm{~J} / \mathrm{g}$ for cotton, $208.4 \mathrm{~J} / \mathrm{g}$ for flax). This peak indicates a phase transformation - the onset of decrystallization, i.e. destruction of the crystalline part of cellulose. The intensive thermal decomposition of fiber waste is characterized by the maximum inclination angle of the TG mass loss curve.

At a temperature of about $360{ }^{\circ} \mathrm{C}$ (Figures 1,2), the amorphization of cellulose pulp of cotton and linen fiber waste with a weight loss of about $50 \%$ occurs. The peak of flax waste and the first peak of cotton waste characterizes the surface ignition of the material. For cotton waste, as for wood materials, first the attenuation, and then the re-ignition of the material, is characterized by the second exothermic peak in Fig. 1. 


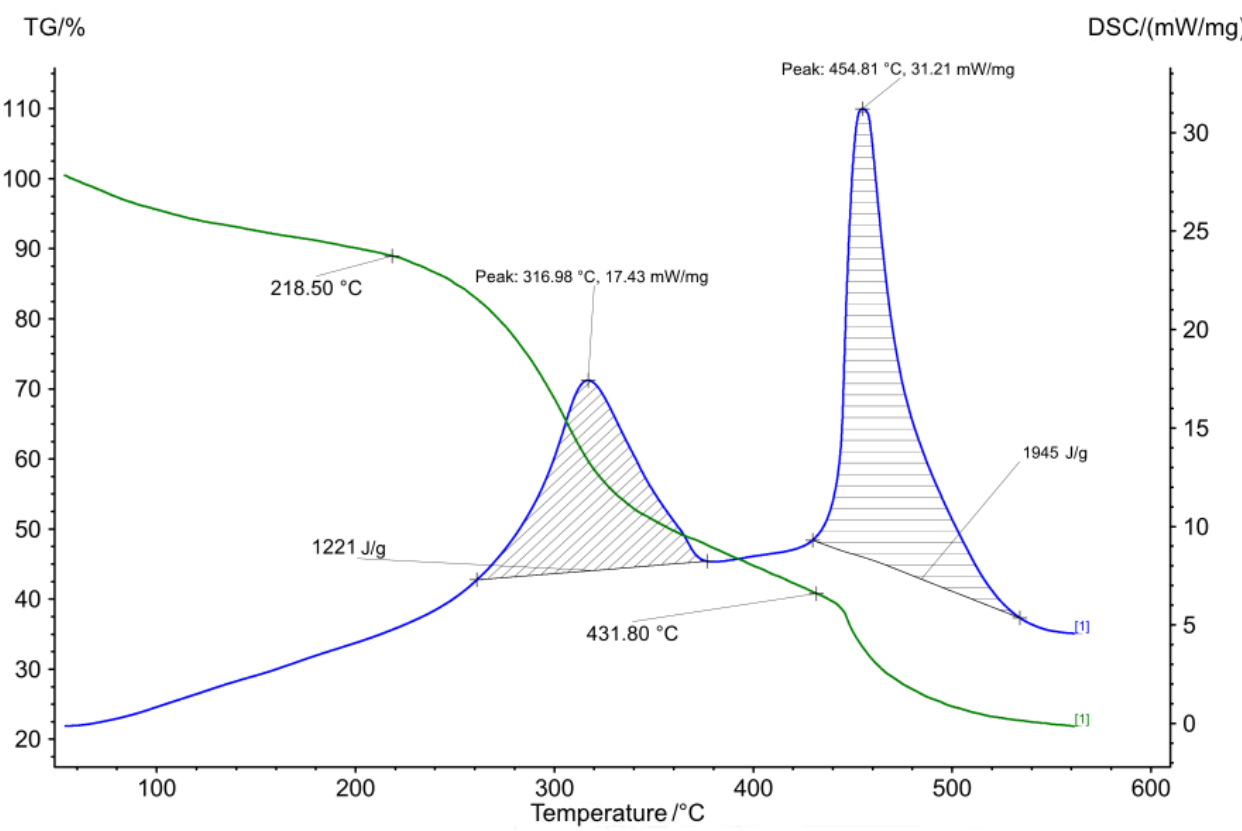

Fig. 1. Curves of TG and DSC waste of cotton fiber.

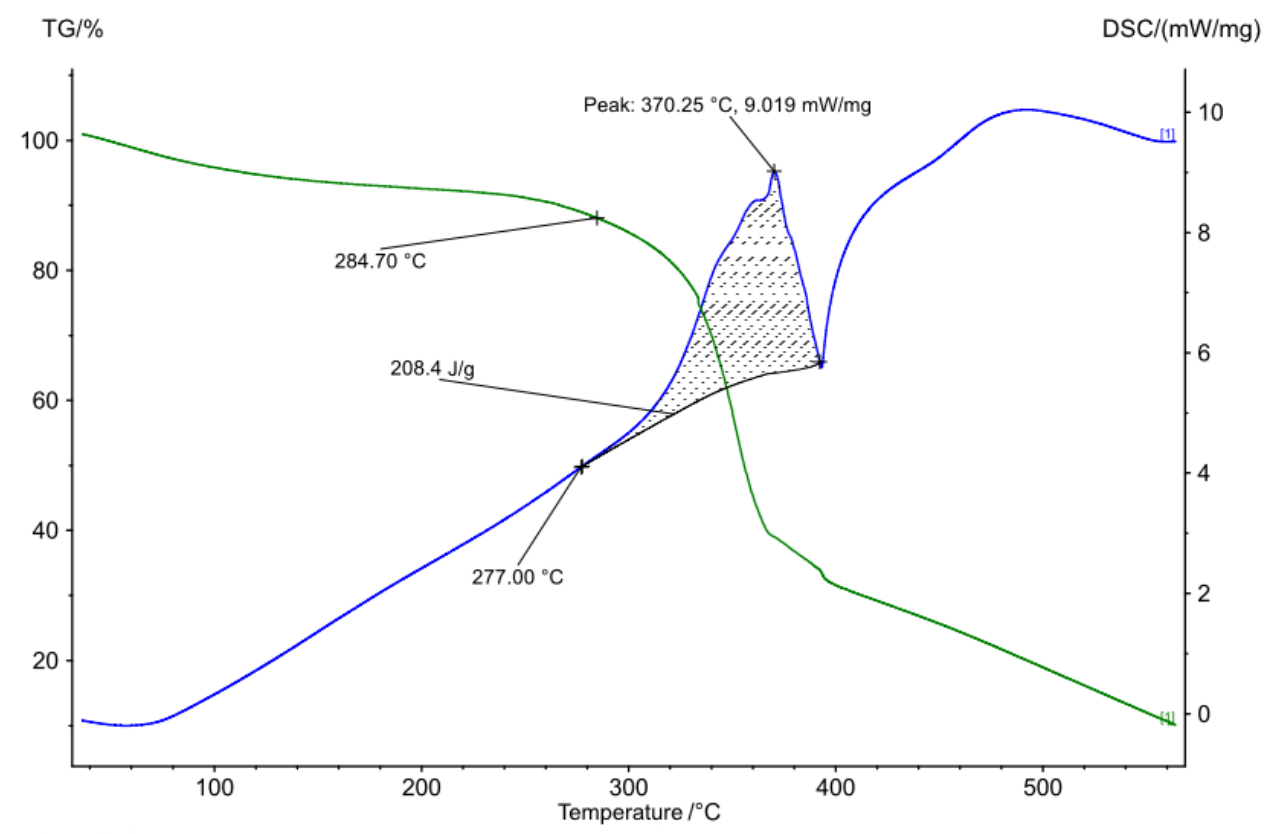

Fig. 2. Curves of TG and DSC of flax fiber waste.

Thus, the high temperature of flaming combustion of flax and cotton waste and the significant loss of mass of the filler material in the fire action require the introduction of flame retardant in the composite structure on the basis of these wastes. The table shows the 
results of determining the weight loss of composite slabs with and without the addition of ammonium fluoride when tested in a "ceramic combustion chamber".

The thermal analysis data are in good agreement with the results of the tests for the loss of mass under fire. With a higher thermal effect during the thermolysis, cotton waste has a higher residual mass than for flax waste. After testing in a "ceramic combustion chamber", plates with filler from waste flax have a higher weight loss. The addition of ammonium fluoride can significantly reduce the loss of mass of the material during combustion.

Table 1. Loss of mass of plates with a filler from plant waste during combustion in a "ceramic combustion chamber"

\begin{tabular}{|c|c|c|c|c|c|c|c|c|}
\hline \multirow{3}{*}{$\begin{array}{l}\text { Type of binder, } \\
\text { portion of } \\
\text { additive, } \%\end{array}$} & \multicolumn{8}{|c|}{$\begin{array}{l}\text { Loss of mass in the combustion of samples with a portion of the } \\
\text { additive } \mathrm{NH}_{4} \mathrm{~F}, \%\end{array}$} \\
\hline & 0 & 10 & 20 & 30 & 0 & 10 & 20 & 30 \\
\hline & \multicolumn{4}{|c|}{ Flax } & \multicolumn{4}{|c|}{ Cotton } \\
\hline PF, 10 & 78.1 & 53.7 & 38.9 & 21.1 & 75.2 & 49.2 & 35.8 & 17.5 \\
\hline PF, 20 & 67.3 & 46.1 & 23.5 & 17.3 & 62.6 & 39.3 & 19.1 & 15.9 \\
\hline PF, 30 & 61.2 & 33.0 & 19.8 & 16.8 & 54.7 & 28.9 & 16.3 & 15.4 \\
\hline UF, 10 & 80.3 & 58.8 & 44.1 & 27.2 & 77.6 & 55.3 & 41.1 & 23.2 \\
\hline UF, 20 & 71.5 & 50.9 & 29.6 & 24.5 & 66.4 & 44.6 & 25.5 & 20.8 \\
\hline UF, 30 & 64.8 & 39.2 & 25.9 & 20.2 & 58.5 & 33.9 & 20.8 & 18.1 \\
\hline
\end{tabular}

The slowing down of the combustion process by ammonium fluoride is caused by chemical inhibition and its effect on physical processes. Thermal action on a material with a halogen-containing flame retardant will produce a large amount of non-flammable gases that reduce the oxygen content, and the burning of most substances ceases with a decrease in the oxygen content in the atmosphere of the protected object to $12 \ldots 15 \%$.

\section{Conclusions}

Thus, the study led to the conclusion that the vegetable filler from the waste products of flax and cotton spinning generates a significant amount of thermal energy under thermal action, and when the fire source is removed, cotton waste, like wood, supports smoldering combustion.

To produce heat-insulating composite plate materials from irrecoverable waste products of cotton and linen fiber, it is rational to use ammonium fluoride with an additive of $30 \%$. Fire protection is achieved by slowing the diffusion of oxygen to the surface, the combustible gases in the reaction zone are diluted with non-flammable gaseous products.

The burning time of the material when removing the flame $0 \mathrm{~s}$, the degree of damage to the mass less than $22 \%$.

\section{References}

1. T. Gurunathan, Smita Mohanty, Sanjay K. Nayak, Composites: Part A 77, 1 (2015)

2. E. Zini, M. Scandola, Polym Compos. 32, 1905 (2011)

3. L.Yan, N. Chouw, K. Jayaraman, Composites Part B: Engineering. 56, 296 (2014) 
4. M. Assarar, W. Zouari, H. Sabhi, R. Ayad, J. M. Berthelot, Composite Structures. 54, 132 (2015)

5. D. A. Soldatov, V. G. Hozin, News of the KSUAE. 1(23), 197 (2013)

6. I. V. Susoeva, T. N. Vakhnina, A. A. Titunin, J. A. Asatkina, Magazine of Civil Engineering 3(71), 39 (2017)

7. L. F. Liu, H. Q. Li, A. Lazzaretto, Renewable and Sustainable Energy Reviews. 69, 912 (2017)

8. R. Stapulionienè, R. Tupčiauskas, S. Vaitkus, S. Vejjelis, Engineering Structures and Technologies. 8(1), 23 (2016)

9. Idumah CI, A. Hassan, Rev Chem Eng. 32, 115 (2016)

10. C. Branca, C. Di Blasi, A. Galgano, Fuel Processing Technology. 162, 20 (2017)

11. D. Battegazzore, J. Alongi, D. Duraccio, A. Frache, Journal of Polymers and the Environment. 1, 14 (2018)

12. J .Zhang, C. A. Wilkie, Polym. Adv. Technol. 16(7), 549 (2005)

13. T. Kashiwagi, R. H. Harris, X. Zhang, R. M. Briber, Polymer. 45(3), 881 (2004)

14. S. Jahromi, W. Gabrielse, A. Braam, Polymer. 44(1), 25 (2003)

15. Y. Tang, Y. Hu, J. F. Xiao, Polym. Adv. Technol. 16(4), 338 (2005)

16. Y. Tang, Y. Hu, B.G. Li, J. Polym. Sci. A Polym. Chem. 42(23), 6163 (2004)

17. X. Zheng, C. A. Wilkie, Polym. Degrad. Stab., 81(3), 539 (2003)

18. L. Song, Y. Hu, Y. Tang, R. Zhang, Polym. Degrad. Stab., 87(1), 111 (2005)

19. G. Camino, Fire Retardant Polymeric Materials, in Atmospheric oxidation and antioxidants, Vol. II, Eds. G. Scott, Elsevier Amsterdam (1993)

20. A. R. Horrocks, D. Price. Fire Retardant Materials CRC Press. 2001. - 442 p.

21. M. Lewin, Polym. Degrad. Stab., 88(1), 13 (2005)

22. S.V. Levchik, E. D. Weil, M. Lewin, Polym. Int., 48(7), 532 (1999)

23. S.V. Levchik, E. D. Weil, Polym. Int., 49(10), 1033 (2000)

24. M. Zanetti, G. Camino, D. Canavese, A.B. Morgan, Chem. Mater., 14(1), 189 (2002)

25. G. Chigwada, P. Jash, D. D. Jiang, C. A. Wilkie, Polym. Degrad. Stab., 88(3), 382 (2005)

26. A. B. Morgan, C. A. Wilkie. Flame Retardant Polymer Nanocomposites. Wiley. 2007. $-451 \mathrm{p}$.

27. S. Y. Lu, I. Hamerton, Prog. Polym. Sci., 27, 1661 (2002)

28. R. M. Aseeva, B. B. Serkov, A. B. Sivenkov. Combustion of wood and its fire hazard properties. 2010. $-262 \mathrm{p}$.

29. Ya. Shestak. The theory of thermal analysis. 1987. - $456 \mathrm{p}$.

30. E. D. Andreeva, M. Yu. Princeva, I. D. Cheshko, Fire safety, 4, 69 (2013)

31. T. N. Vachnina, I. V. Susoeva, E. B. Anosowa, A.V. Kapranov, News of the KSUAE 1(39), 188 (2017)

32. M. Yu. Princeva, I. D.Cheshko, Fire safety, 3, 96(2014) 